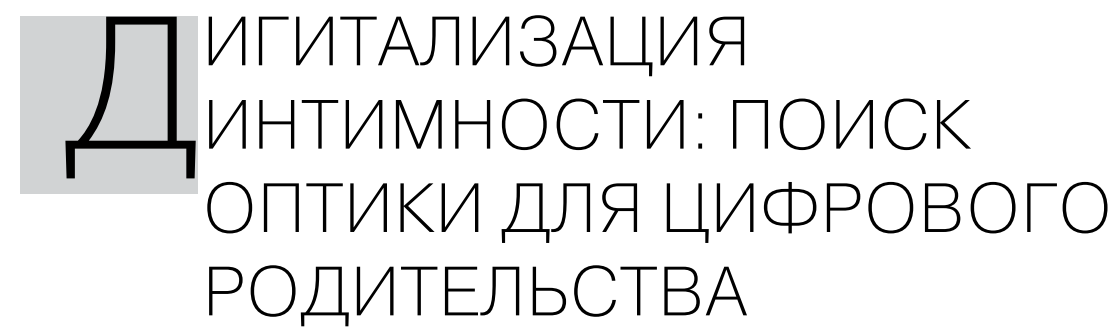

\title{
Елена Лактюхина
}

Елена Лактюхина, кафедра социологии и социальных технологий, Волгоградский государственный университет. Адрес для переписки: ВолГУ, Университетский пр., 100, Волгоград, 400062, Россия. laktyukhina@volsu.ru.

Исследование выполнено в рамках научного проекта № 18-011-00692 «Родительство в эпоху "умных вещей": социологический анализ» при финансовой поддержке РФФИ.

В представленном обзоре проводится теоретический анализ формирования исследований цифрового родительства. Условно материалы по теме могут быть разделены на два корпуса текстов: о безопасности детей в цифровом пространстве и об обеспечении безопасности детей с помощью цифровых средств наблюдения в повседневной жизни. Анализируя современные концепции цифрового родительства, автор в большей степени сконцентрирован на второй проблеме. В работе анализируются вопросы о теоретических истоках и преемственности в концептуализации феномена цифрового родительства. Исходя из тезиса о том, что новая социология детства, ставшая основным двигателем развития исследований родительства, методологически связана с социологией повседневности, автор обращается к ее главным концепциям - структуралистскому конструктивизму Пьера Бурдье и фрейманализу Ирвинга Гофмана. Цель работы - проанализировать базовые концепты социологии Бурдье и Гофмана в качестве методологических ресурсов концептуализации цифрового родительства. Обращаясь к бурдьевистской оптике, автор использует следующие концепты: социальные агенты, социальные отношения, ресурсы, социальные практики и физическое пространство. Установление связей между ними позволяет увидеть большую часть поставленных проблем в области цифрового воспитания, появившихся в последние годы. В частности становится понятной одна из наиболее распространенных трактовок: цифровое наблюдение родителей за детьми определяется как проявление отношений доминирования - асимметричного распределения властных ресурсов между группами агентов - детьми и родителями. В теоретической рамке, предложенной Гофманом, технологические устройства, которые используют родители для контроля над детьми, рассматриваются как вещи, фреймирующие это взаимодействие. Концептуализация в логике фрейм-анализа строится вокруг организации наблюдения как процесса конституирования повседневных практик детей и родителей.

Ключевые слова: цифровое родительство; умные вещи; детская мобильность; детский монитор; родительство; детство; приватность 


\section{ВВЕДЕНИЕ: ПОСТАНОВКА ПРОБЛЕМЫ}

Первого марта 1932 года в семье американского героя-летчика, совершившего первый одиночный перелет через Атлантический океан, Чарльза Огастеса Линдберга случилась трагедия: младший сын, полуторагодовалый Чарльз, был похищен. Злоумышленники оставили записку с требованием выкупа. Выкуп был выплачен, но ребенка так и не вернули, позже он был найден мертвым. $0 б$ этом событии написали газеты по всему миру, оно стало сюжетом литературных произведений и поводом для принятия Конгрессом США нового закона о похищении людей, но главное то, что это событие связывают с появлением нового технического устройства. Юджин Ф. Макдональд младший, один из учредителей Zenith Electronics, движимый впечатлением от происшествия, просит своих инженеров изобрести устройство, которое даст ему возможность слышать новорожденную дочь, находясь в другой части дома. Новый гаджет назвали «радионяня», он поступил в продажу в 1937 году. Сигнал этого устройства перебивался другими радиочастотами, и само оно стоило довольно дорого, что не способствовало его популярности. Однако через пятьдесят лет с распространением беспроводных технологий, в особенности радиотелефонов, обновленная радионяня стала основным радиоустройством для родителей младенцев. Главные опасности, от которых должна была уберечь радионяня, - похищение и синдром внезапной детской смерти (CBДC/SIDS). Несмотря на преувеличенность первой и невозможность предотвратить с помощью радионяни вторую, устройство становится крайне популярным среди молодых родителей. Сегодня на цифровом рынке в изобилии представлены модификации радио-и видеонянь, «слушающих» ребенка, измеряющих его температуру, а также множество переносных устройств для наблюдения за детьми, которые уже вышли из младенческого возраста.

Включение цифровых технологий в практики воспитания, использование цифровых устройств во взаимодействии родителей с детьми и уходе за ними получило название цифрового родительства (digital parenting). Новый вид воспитания включает два главных направления деятельности родителей: обеспечение безопасной среды для детей в интернете (родительская медиация между ребенком и интернет-пространством) и обеспечение безопасности ребенка путем цифрового наблюдения за ним как в интернете, так и в обычной жизни. В отношении доминирующих средств массовой информации второй половины XX века потенциальные риски изучались в первую очередь в ходе социально-психологических исследований воздействия телевидения на когнитивные способности и эмоциональное поведение детей. Чаще всего акцент ставился на негативном влиянии СМИ, со временем более сложные исследовательские модели выявили множество путей воздействия СМИ, стали разрабатываться темы родительского посредничества (в том числе детская медийная грамотность) и дифференциации жизненных шансов детей в зависимости от доступа к СМИ (Lemish 2015; Valkenburg and Peter 2013). С развитием цифровых технологий, интернета и социальных сетей в последние два десятилетия исследования в области детей и медиа, а также собственно цифрового родительства, 
отчасти наследуют традицию сосредоточения на рисках и негативном влиянии использования детьми (и в отношении детей) новых медиа. Этот вопрос также оказался в центре общественного и политического дискурса. Однако в последние несколько лет формируется еще одна тенденция: переосмысление проблемы с точки зрения прав детей: «В 2014 году исполнилось двадцать пять лет Конвенции 0ОН о правах ребенка (1989) и Всемирной сети. Это совпадение стимулировало всплеск активности среди исследователей и политиков, заинтересованных в связях между управлением интернетом и благополучием детей» (Livingstone 2016:5). Одни исследователи делают акцент на правах ребенка «искать, получать и передавать информацию» (Конвенция о правах ребенка 1989), доступ к сети они связывают с образовательными, коммуникационными, социализационными ресурсами (Star and Bowker 2006); другие - на рисках, связанных с нарушением неприкосновенности личной жизни ребенка, с уязвимостью перед киберпреступностью, на важности защиты от дискриминации, насилия и т. д. (Jeffery 2020). Эти два корпуса текстов различаются по своим исследовательским подходам, концептуализации новых медиа и детства. Первые в большей степени сосредоточены на новых эффектах использования медиа: возможности для учебы, игры, выражения творческого потенциала (Barron et al. 2009; Brito et al. 2017). Такая исследовательская позиция встречает критику, связанную с тем, что формальное признание прав детей не обеспечивает условий их исполнения, рекомендации, разработанные на глобальном Севере, могут быть контрпродуктивны на глобальном Юге (Hanson 2014; Livingstone and Bulger 2014; Моуn 2011). Исследователи рисков цифрового родительства более критично оценивают права детей (Моуn 2011). Поднимаются вопросы о том, в какой степени новые технологии усугубляют существовавшие риски детской повседневности и формируют новые (Livingstone, Haddon, and Gorzig 2012); какие риски несет включение детей в экономические процессы через использование новых медиа (Holloway and Green 2016); как должны регулироваться права детей на неприкосновенность частной жизни, на забвение и удаление размещаемого родителями медиаконтента о детях, который последние могут позже счесть компрометирующим (Dias and Brito 2020; Leaver 2017; Leaver and Highfield 2018; Mascheroni, Ponte, and Jorge 2018).

В целом исследования цифрового родительства имеют общие корни - так называемый поворот к детству в социальной теории. Благодаря ему дети начинают восприниматься как полноправные социальные агенты, чьи психологические потребности и юридические права необходимо учитывать. Эта новая аналитическая перспектива оформляется в 1980-1990 годы. Ее идеологи активно критикуют «социализационную теорию», в основании которой представления социологов-классиков о ребенке как о дикаре, требующем вложения стороннего труда, чтобы стать полноценным человеком (Ambert 1986; Matthews 2007). Отводя детству роль «черного ящика», из которого «выходит» готовый член общества, социологи уступали эту нишу педагогике и психологии развития. Эти дисциплины надолго закрепили за детством представления о нормальности и отклонении от нормы на основании своих знаний об «универсальной природе ребенка». 
Новая социология детства, не отрицая крайнюю зависимость человеческого младенца в целом (по сравнению с другими приматами), которая легла в основу классической социализационной теории, все же исходит из утверждения, что дети вовсе не являются tabula rasa, а с рождения обладают социальной «прошивкой» (Pinker 2002). Эта социальная «прошивка» - способность интерпретировать социальный мир и действовать в соответствии со своими интерпретациями. «Там, где традиционная социология видит только “становящихся акторов", или будущих проводников социального действия, которых еще предстоит встроить во взрослый социальный порядок, адепты “нового взгляда" усматривают акторов состоявшихся, или творцов и участников социальных интеракций, созидающих реальность здесь и теперь. Упор делается не на подготовку детей к будущему, а на их способность к качественному и значимому взаимодействию в настоящем» (Якимова и Евсеева 2011:13). Взгляд на детство через идею универсальной природы ребенка не позволял говорить о том, что дети переживают (и проживают) этот период по-разному в зависимости от многих, требующих разъяснения, факторов. Следовательно, любые описания жизни детей с началом новой концепции должны конкретизировать, какое именно это описание: каких детей и при каких обстоятельствах? Благодаря этому родительство находит свое место в социальной теории как объект исследования, в фокус внимания попадает взаимодействие ребенка со взрослым, от действий и индивидуальных выборов которого зависит траектория развития детства (Matthews 2007).

Начиная с работ скандинавских социологов Йена Квортрупа (Qvortrup 1991) и Лины Аланен (Alanen 2005), детство становится сконструированной категорией, равной классу или гендеру. Исследователи предлагают изучать детство как категорию меньшинства, члены которого маргинализированы по отношению к взрослому обществу и подвергаются патерналистскому обращению. Так же, как гендерные или классовые исследования, социология детства подвергается постоянной экспансии со стороны борцов за социальное благополучие детей в лице юристов, психологов и социальных работников. Эта риторика отражается и на социологических исследованиях. Крис Дженкс (Jenks 1996) предлагает вместо периода социализации рассматривать детство как «развитие через зависимость». Дэвид Олдман (Oldman 1994) концептуализирует взаимодействие взрослых и детей как социальные классы, которые существуют главным образом благодаря их экономической противоположности друг другу и способности доминирующего класса (взрослых) экономически эксплуатировать деятельность подчиненного класса (детей). Такое переплетение теоретических концептуализаций и правовых дискуссий вызвано параллельным развитием социологии повседневности, сделавшей актуальными исследования маргинальных групп (к которым были отнесены и дети) и правовой либерализации, выразившейся в появлении законов о защите прав детей и развитии в европейских странах института детского омбудсмена.

Методологический поворот, способствовавший созданию новой социологической субдисциплины, является закономерным развитием логики науки. К тому времени уже прошла теоретическая ревизия классических социологических кон- 
цепций. Произошел поворот к повседневности, выразившийся в «отказе от апелляций к социетальным (общественным) структурам и процессам, в акцентировании повседневной укорененности социальной реальности, в переходе от интуиции вечного, тотального и всепроникающего Общества к интуиции подвижной и свободно координируемой повседневной интеракции» (Вахштайн 2011:7-8). Результатом критики «больших» объяснительных концепций стал новый теоретический консенсус вокруг категории практик. Ренессанс переживают подходы, предложенные в работах Пьера Бурдье, Энтони Гидденса, Гарольда Гарфинкеля, Ирвинга Гофмана. Оформление социологии детства в качестве субдисциплины тесно связано с развитием социологии повседневности и ее аксиоматики. Цель этой статьи - проанализировать базовые концепты социологии Бурдье и Гофмана в качестве методологических ресурсов концептуализации цифрового родительства.

\section{ЦИФРОВОЕ РОДИТЕЛЬСТВО В БУРДЬЕВИСТСКОЙ ОПТИКЕ: АГЕНТЫ, РЕСУРСЫ И ПРОСТРАНСТВА}

Большинство исследований новой социологии детства выполнены в рамках структуралистского конструктивизма (Buhler-Niederberger 2010; Holloway and Green 2016), об этом свидетельствуют программные тексты новой парадигмы, и мы сами легко узнаем язык Бурдье даже при поверхностном знакомстве с этими исследованиями. Однако в настоящее время, очевидно, требуется ревизия теоретических основ социологи детства. Необходимо прояснить последствия теоретической экспансии конструктивистской оптики для социологии детства. Кроме того, нужна новая концептуализация родительства и воспитания в рамках новой социологии детства, этого требует логика развития социологии: в самой теории повседневности произошли существенные изменения, нельзя игнорировать современные социальные исследования технологий и социологии мобильности, оказавшие влияние на исследования повседневности.

Обратимся к концептуализации детства, как она представлена у Бурдье, чтобы прояснить базовую аксиоматику направления. Предложенная им система координат состоит из социальных агентов, социальных отношений, ресурсов, социальных практик и физического пространства. Расчленение их на элементы анализа (предикативные характеристики) и установление связей между ними позволяет увидеть бо́льшую часть поставленных проблем в области цифрового воспитания, появившихся в последние годы. Так, например, цифровое наблюдение родителей за детьми определяется как проявление отношений доминирования - асимметричного распределения властных ресурсов между группами агентов: детьми и родителями. Само наблюдение асимметрично, к тому же нередко дети не знают, что за ними наблюдают. Например, функция так называемого одноканального соединения, которой снабжены некоторые модели smart watch, включается незаметно для обладателя часов и позволяет услышать все, что происходит в этот момент. В последние годы в ряде европейских стран возникали судебные разбирательства, связанные с этой функцией, однако все они касаются нарушения прав окружающих ребенка взрослых, чьи разговоры могут быть услышаны без 
их согласия, но не учитывают права самого ребенка (Forbrukerrådet 2017). Это обстоятельство подтверждает низкий социальный статус детей в публичном пространстве. Множество исследований посвящено тому, как выстраиваются отношения между родителями и детьми в зависимости от характеристик агентов. Так, например, в родительском посредничестве в использовании новых медиа отмечают следующие тенденции: использование медиа детьми младшего возраста опосредуется чаще, чем в отношении подростков (Valkenburg et al. 1999). Есть также зависимость и от уровня образования: родители с более высоким уровнем образования лучше осведомлены о потенциальных рисках и преимуществах воздействия медиа и активнее контролируют деятельность детей в интернете, однако родители с более низким уровнем образования чаще выступают посредниками в цифровых играх детей (Livingstone 2002; Notten and Kraaykamp 2009; Roe 2000). Проверка контактов и мониторинг посещаемых ребенком страниц в интернете чаще проводится более молодыми родителями у детей младшего возраста (до 8 лет), чем старшего (9-16 лет), и наоборот - в случае с более зрелыми родителями (Sonck, Nikken, and de Haan 2014). Девочки воспринимают себя находящимися под наблюдением чаще, чем мальчики. Наконец, чем разнообразнее деятельность детей в интернете, тем больше родители следят за ней с использованием медиаресурсов (Sonck et al. 2014).

Задав исследовательский вопрос «как детско-родительские отношения, реализуясь в практиках контроля, изменяют городское пространство?», мы получим сетку различений, которая «ухватит» детские места в городе и борьбу двух групп агентов за городское пространство. Джейн Джекобс иллюстрирует эту борьбу, приводя тексты отчетов городских планировщиков: «Тщательная проверка в радиусе 1/4 мили от игровой площадки при выполнении обширного перечня условий во многих больших городах обнаружила на этих площадках лишь около 1/7 детского контингента в возрасте от 5 до 15 лет.... Улица - соблазнительная приманка и сильный конкурент.... Чтобы успешно конкурировать с городскими улицами, где кипит жизнь, сулящая приключения, необходим высокий уровень управления игровой площадкой. Способность сделать игру на ней настолько привлекательной, чтобы дети приходили с улиц и оставались на площадке день за днем, - редкое свойство игрового руководителя, требующее соединения ярких личных качеств и прекрасной технической подготовки» (2011:110). В этой «борьбе» Джекобс явно выступает на стороне группы агентов, представленной детьми: «Притягательность уличной жизни для городских детей была давно замечена экспертами по отдыху и развлечениям, причем замечена, как правило, с неодобрением.... Этот же отчет критикует упрямую склонность детей “болтаться" вместо того, чтобы играть в “приемлемые игры”. (Приемлемые для кого?) Эта тоска по Организованному Ребенку со стороны желающих загнать стихийную игру в жесткие рамки, как и детское упрямое желание болтаться по улицам, где кипит жизнь, сулящая приключения, столь же характерны для наших дней, как для 1928 года» (110).

Материальным воплощением этой борьбы является сокращение площади тротуаров и повсеместное распространение специальных детских мест - площа- 
док. Новые места для досуга детей связаны с новыми практиками контроля их поведения. Если контроль детей на городских улицах вменяется каждому проходящему мимо взрослому, то на специальных территориях (парках или площадках) этот контроль осуществляется специально нанятыми людьми (или, по крайней мере, им вменяется). При этом обмен территориями не эквивалентен: на тротуарах дети в большей мере являются хозяевами территорий, например, не позволяют на них парковаться, а парк является еще и опасной для детей территорией за счет слабой включенности в городское пространство и слабого контроля. То есть дети выбирают места, где они в большей мере включены в городскую повседневную жизнь; несмотря на то, что на городских улицах они находятся под контролем взрослых, этот контроль разделен между анонимными прохожими, в отличие от парков и площадок, где контролирующие взрослые всегда определены и известны.

Но что происходит, если городское пространство становится местом повсеместного цифрового контроля? Распространение средств слежения заставило многих исследователей вспомнить Мишеля Фуко. Расширение функций социального контроля на все сферы жизни общества им описано как «прививка тюремного вируса всему социальному организму» (Foucault 2009). По его мнению, тандем «тюрьма - преступник» сменяется новым: «Контроль - отклонение от нормы». «0бщество нуждается в более гибких методах надзора за правонарушителями, чем содержание их в классической тюрьме... Нынешнее общество в состоянии обезопасить себя, минуя тюремную кузницу криминальных элементов, - с помощью тщательного мониторинга социальных девиантов...» (Якимова и Евсеева 2011:27-28). Этот всеохватывающий мониторинг касается каждого жителя города. Жиль Делез (2004) называет этот процесс сменой дисциплинарного общества, Фуко - обществом контроля (Foucault 2009). Паноптикон общества контроля не выглядит как тюрьма, его составляют городская система видеонаблюдения, цифровые устройства, собирающие данные о своем пользователе, серверы, аккумулирующие эти данные, и т. д.

Практики мониторинга отдельной сферы жизни человека или социальных групп не составляют самостоятельной сети. Так, мониторинг детского поведения родителями посредством цифровых технологий вписывается в общую систему городского наблюдения. Эти устройства слежения за детьми в случае потери сигнала GPS определяют местоположение пользователя, улавливая сигналы станции сетей сотовой связи (LBS). Станции сотовой связи, Wi-Fi-сеть, спутниковые системы навигации, городские камеры слежения образуют инфраструктуру, которая существует, подобно бентамовскому паноптикону, вне зависимости от того, есть ли в его камерах заключенный и надзиратель в башне. Родители и дети только подключаются к уже существующей сети глобального наблюдения в качестве агентов с различным статусом.

Если дети постоянно носят с собой (или на себе) устройство, непрерывно передающее родителям информацию о месте их нахождения, то как теперь нам определить «недетские» и «детские» места, если прежде критерием последних была «просматриваемость»? Предположим, что предметом борьбы детей и под- 
ростков до внедрения в их повседневность сообщающих об их местонахождении устройств являлись не конкретные места (улицы или пустыри против дворов и парков), а ресурсы, которым они обладали (и этот ресурс - приватность), то какие места теперь становятся привлекательными для детей и через какие практики они получают к ним доступ?

Как правило, детские места в городе образуют «треугольник», сохраняющий свою конфигурацию уже не один десяток лет. В своей работе о дрейфе Ги Дебор (1958) цитирует Шомбера де Лове: «“Каждый индивидуум живет ... внутри географической области чрезвычайно малого радиуса". Для этого строится диаграмма перемещений, сделанных в течение одного года студенткой, живущей в 16-м округе. Маршрут студентки образует маленький треугольник, без значительных отклонений, с вершинами: “Школа политических наук - дом - учитель музыки"». Современные дети и подростки, как правило, перемещаются по тому же «треугольнику», что и приведенная в пример студентка: дом, школа и место, где они получают дополнительное образование, или спортивная секция. Однако несмотря на то, что их жизнь «трогательно ограниченна», пешие перемещения между этими точками приобретают ценность и становятся эквивалентом фланерства. Впрочем, эти перемещения ценны только тогда, когда скрыты от наблюдения. Как этого можно достичь в условиях постоянного цифрового наблюдения? Родители, чьи дети пользуются отслеживающими перемещения приложениями для смартфонов, описывают следующую ситуацию: дети в течение дня иногда «пропадают» с виртуальной карты, но когда они должны быть в определенном месте в определенное время (например, у репетитора в восемнадцать часов) они, добравшись до нужного места, снова заходят в приложение, оставляя «правильные» цифровые следы (Сергеева и Лактюхина 2019). То же касается и дрейфа в интернете. Подростки стремятся использовать интернет вне поля зрения своих родителей, в своей комнате или вне дома со своими сверстниками (Livingstone and Bovill 2001). Родители, в частности, не могут ответить точно на вопрос, что их дети делают в интернете, часто не используют активно приложения для онлайнобщения, которыми пользуются их дети (Duimel and de Haan 2007). Кроме того, мнения детей и их родителей относительно безопасного и вредного медиаконтента, как правило, не совпадают. Родители также слабо осведомлены о содержании игр и онлайн-мероприятий для детей, что приводит к большему беспокойству и стремлению ограничить присутствие детей на этих онлайн-площадках (Livingstone and Bovill 2001).

Бурдьевистская концептуализация родительских практик не лишена практической ценности, она позволяет увидеть борьбу коллективных и индивидуальных агентов за ресурсы и ее результаты, запечатленные в городском пространстве. Но такой взгляд ограничен размещением оснований практик или во внешнем принуждении, или во внутренних диспозициях (габитусе). Оптика, заданная Бурдье, позволяет увидеть сам практический акт, «уже содержащий в себе условия своего свершения или конституирующий их в процессе осуществления» (Вахштайн 2011:41), но не позволяет увидеть его контекст. Проблему контекста, его заданности и интерпретации ставит Гофман и концепция фрейм-анализа. 


\section{ТРАНСПОНИРОВАНИЕ И ФАБРИКАЦИЯ: МЕЖДУ КОНТРОЛЕМ И ЗАБОТОЙ}

Технологические устройства, которые используют родители в отношении своих детей, могут быть рассмотрены как рамки этого взаимодействия. Концептуализация в логике фрейм-анализа будет строиться вокруг «фреймовой организации наблюдения как процесса конституирования повседневных событий» (Вахштайн 2011:152). «Три фундаментальных и не сводимых друг к другу теоретических основания теории фреймов тесно взаимосвязаны: наблюдение - событие фрейм» (154). «Первичная система фреймов являет собой как раз то, что обнаруживает нечто осмысленное в тех особенностях сцены, которые в ином случае не имели бы никакого смысла» (Гофман 2004:81). Другими словами, «фрейм представляет собой матрицу свершающихся в пространстве и времени событий, и одновременно схему их интерпретации наблюдателем» (Вахштайн 2011:195). В отношении цифрового родительства мы можем поставить следующий вопрос: в каком фрейме происходит событие цифрового контроля детского поведения?

В 1982 году судья города Альбукерки штата Нью-Мексико (США) Джек Лав просматривал комикс о Человеке-пауке. Сцена, в которой злодей Кингпин прикрепил на руку главного героя браслет, с помощью которого можно узнавать, где он находится, натолкнула судью на мысль об устройстве, способном сократить число заключенных в тюрьмах. Судья Лав обратился к своему другу-компьютерщику - и уже через год браслеты тестировались на четырех заключенных местной тюрьмы. В настоящее время во всех штатах США и во многих европейских странах применяют цифровые браслеты для слежения за осужденными по «легким» статьям и за несовершеннолетними преступниками. Эти браслеты не позволяют преступникам покидать определенные территории, подавая сигнал в полицию. Изобретение призвано предотвращать побеги и повторные преступления без заключения в тюрьму, что заставляет вспомнить традицию клеймения преступников.

Гофман говорит о том, что «любой фрагмент человеческой деятельности, представляющий собой организованную активность, подвержен двум способам трансформации и порождает два процесса последовательного реплицирования: настройки (keying) и фабрикации (fabrications) (каждый из этих процессов способен заполнить мир множеством копий). Что бы ни происходило “на самом деле", трансформация предполагает эти два типа преобразования» (Гофман 2004:217). Первый из них - переключение, или транспонирование - представляет собой «набор конвенций, посредством которых определенная деятельность, уже осмысленная в терминах базовой системы фреймов, трансформируется в иной, с точки зрения участников, вид деятельности» (104). Переключение возможно для действий, уже осмысленных в определенной схеме интерпретаций, участники должны знать об этом преобразовании смысла, начало и конец трансформации отмечаются временными рамками или «скобками» (106). Является ли гаджет, представляющий собой браслет с геолокацией, который передает данные «наблюдателю» (в нашем случае - родителю) и оповещает о пересечении пользователем заданных границ, результатом транспонирования фрейма контроля перемещений преступников? В «преступный» фрейм укладывается и функция однока- 
нального звонка (прослушки), позволяющего без ведома пользователя слышать его разговоры и все, что происходит вокруг. Согласно многочисленным отзывам родителей об этом гаджете, они часто не рассказывают своим детям обо всех функциях их часов, в частности - о прослушке. Можно сказать, что этот вид трансформации содержит в себе элемент введения в заблуждение. Намеренное искажение или введение в заблуждение предполагает второй вид трансформации фабрикация. Фабрикацией Гофман называет «действия одного или нескольких индивидов, направленные на то, чтобы изменить ситуацию таким образом, чтобы у других людей создалось ложное представление о происходящем». «При этом, продолжает Гофман, - как правило, замышляются интрига или заговор, успешное осуществление которых приводит к существенному искажению реальности» (145). «Каждая следующая трансформация - это усиление знаковых элементов события, превращение события в знак самого себя. Таким образом, каждое следующее наслоение в структуре взаимодействия дается легче предыдущего.... А потому за переключением легко может последовать фабрикация. (И наоборот, переключение может стать элементом фабрикации, ее “внешним слоем”, “отвлекающим маневром", маркером фигуративности)» (Вахштайн 2011:212).

«Скрытое наблюдение» есть форма вмешательства (containment), представляющая собой разновидность фабрикации. В ситуации скрытого наблюдения «индивид занимает положение, в котором его можно дискредитировать (и тем самым осуществить определенную фабрикацию)» (Гофман 2004:228). Поведение индивида оценивается наблюдающим родителем. Он выступает в роли контролирующей инстанции, наделенной правом вмешиваться и регулировать поведение ребенка. «В этом отношении шанс услышать или увидеть что-либо существенное уже предполагает обретение некоторой способности разрушения - разумеется, речь идет не о том, чтобы разрушить уже свершившееся действие, а о том, чтобы разрушить действие предстоящее. Поскольку наблюдающий (monitor) не позволяет наблюдаемому (monitored) знать о том, что за ним ведется наблюдение (это вполне обычное дело), данная ситуация представляет собой специфическую разновидность вторичного вмешательства (recontainment), где поведение наблюдающего ориентировано на создание ловушки (trap), ориентированной на предстоящее поведение наблюдаемого» (228).

«Такие средства коммуникационной защиты, как стены и расстояния, а также попытки избавиться от посторонних глаз и ушей, казалось бы, служат гарантией от дискредитации. Однако любое наблюдение за поведением любого человека, не догадывающегося, что за ним наблюдают, имеет дискредитирующую силу; все без исключения формы тайного наблюдения направлены на то, чтобы трансформировать последующую деятельность человека в подлежащий дискредитации спектакль (performance) и тем самым разрушить ее» (Гофман 2004:231). Эта форма фабрикации позволяет родителям корректировать публичное поведение ребенка в ситуациях, когда они не находятся рядом с ним. Однако «скрытым» такое наблюдение будет недолго, после первого вмешательства в поведение ребенка (путем последующего комментирования его «подслушанных» высказываний) оно становится явным. Свое дальнейшее поведение ребенок будет корректировать с учетом 
того факта, что все, что он скажет, может быть услышано родителями. Но объектом скрытого наблюдения является не только ребенок. С помощью детского гаджета прослушивается и воспитатель детского сада, няня или школьный учитель. Это средство установления типичных практик, способ выявить и квалифицировать типичное рутинное поведение взрослого, имеющего воздействие на ребенка. По отношению к последнему это является элементом заботы, а по отношению к окружающим взрослым - средством контроля.

Ситуация смешения дискурсов заботы и контроля в отношении детей обнаруживается во многих областях. Примером могут служить законы, регламентирующие детскую мобильность. Правовая практика ограничения мобильности детей в США сложилась в конце XIX века как мера борьбы с подростковыми бандами, позже получившая иную интерпретацию и рассматривавшаяся как забота о детях (Cresswell 2006). С 2009 года по настоящее время закон о комендантском часе действует и в России, защитники этого закона приводят статистические данные, свидетельствующие о снижении и преступлений, совершенных с участием детей, и преступлений против них. Обнаружив фреймы, относящиеся и к контролю, и к заботе, мы можем расположить все фреймирующие элементы, связанные с цифровыми родительскими практиками, на системе координат, где по одной оси располагается полицейский контроль, по другой - родительская забота.

Если же мы обратимся к истории создания детских мониторов, то увидим, что многие из них были разработаны родителями детей с особенностями развития. Одни устройства совмещают функции многих медицинских гаджетов: измеряют температуру, частоту сердечных сокращений у ребенка, проводят некоторые виды медицинских анализов и многое другое. Эти мониторы представляют собой доместицированные медицинские приборы (Laktyukhina 2018). Они поддерживают фрейм медицинского ухода за недоношенными и больными младенцами, будучи помещенными в мир повседневного ухода за обычными детьми. Их первые пользователи - дети с заболеваниями сердца, органов дыхания и т. д. (примером может служить умный носок Owlet). Другие устройства направлены на определение геолокации и обеспечение экстренной телефонной связи. Они разрабатывались для детей с ментальными отклонениями. Но прежде чем эти устройства стали детскими, они предназначались для стариков, нуждающихся в следящем гаджете в силу уязвимости, которая возрастает у них при болезнях Альцгеймера и Паркинсона. Разбирая функции smart watch, мы получим описания наслоений одной трансформации на другую, а само использование гаджета станет многократным переключением, чередованием фреймов или осциллированием между этими функциями. Каждая из используемых функций цифрового устройства фреймирует взаимодействие ребенка и родителей. Построив шкалу различений и собрав эмпирические данные об использовании гаджетов родителями, мы увидим, каких фреймирующих элементов в этом взаимодействии больше. Но все это множество функций закрывает от внимания сам материальный объект, носителем которого он является. Согласно фрейм-анализу, материальное оборудование тоже требует интерпретации. «Материальный объект в конструкции социального события играет исключительно важную, но далеко не главную роль - роль видимого “якоря", на 
котором держится фрейм. Материальные объекты удерживают границы социальных ситуаций, служат своего рода маркерами ситуации - метакоммуникативными сообщениями. Они говорят участнику взаимодействия, что именно здесь происходит» (Вахштайн 2013:18-19).

Детские smart watch часто называют детским телефоном, но внешне на телефон они похожи меньше всего и выглядят именно как часы (благодаря чему и получили свое название). Это устройство, в отличие от мобильного телефона, труднее разбить или утопить (благодаря материалам, из которых оно изготовлено), труднее потерять, благодаря датчику снятия с руки. К материалам, из которых изготавливаются ремешки детской «носимой» электроники, предъявляются высокие требования: они должны быть экологичными, это их роднит с детскими игрушками для малышей, которые те неминуемо пробуют на вкус. К тому же устройства имеют «детский» дизайн: яркие цвета и изображения героев мультфильмов на корпусе или экране. Этот гаджет становится своего рода телефоном «в теле» игрушки. Игровую оснастку поддерживает и одна-две компьютерных игры, которые часто присутствуют в перечне функций гаджета. Родственным устройством являются детские телефоны в виде игрушек (например, TeddyFone - телефон в форме медведя). Но взаимодействие ребенка со smart watch не становится событием «игра с игрушкой». Операции родителей в этом приложении напоминают игру гораздо больше. Детское устройство не «ограничивается» одним лишь браслетом на руке ребенка - продолжением их является приложение в смартфоне родителей, без которого использование гаджета невозможно. Доступ ко всем функциям находится на главном интерфейсе, зайдя в поле «карта» или «след», родитель видит карту города (конкретного квартала), на которой линиями прочерчен маршрут перемещений ребенка. Самого ребенка обозначает нарисованная фигурка человечка (в некоторых моделях ее можно заменить фотографией). Родитель следит за перемещениями «виртуального героя» карты, если тот нарушает правила - пересекает границы виртуального забора (зоны, отмеченной как легитимная для перемещений, например, двора), родитель получает об этом оповещение и может дать сигнал ребенку, чтобы тот вернулся в отмеченную «зону»; для поощрения прилежного соблюдения правил ребенком предусмотрена система награждений «лайки», которые ставит родитель.

\section{ЗАКЛЮЧЕНИЕ}

Атрибутика и логика компьютерной игры задана самим объектом (и его инженером), а не интерпретатором. Брюно Латур и Мадлен Акриш описывают это через понятие модальности. «По существу, в устройство закладывается определенная программа действия, или нарративная программа, которая затем начинает обуславливать действие людей. При этом, что существенно, во взаимных вписываниях людей и техники доминирует модальность долженствования: “быть должным что-либо осуществить"» (цит. по: Напреенко 2015:113). Размышляя в этой логике, мы можем предположить, что родители четко обозначают территорию для перемещений детей, потому что программа им предлагает это сделать, дисципли- 
нируют ребенка, потому что программа маркирует выход из заданной зоны как нарушение, подавая сигнал тревоги (в противном случае родители даже не узнали бы о совершенном нарушении), родители одаривают ребенка лайком, потому что программа квалифицирует поведение ребенка как достойное похвалы, и ребенок, принимая логику и правила игры, не нарушает правила и «собирает» лайки (сама инструкция приложения предлагает родителям поощрять ребенка подарком за определенное количество полученных лайков). Возможность сделать телефонный звонок, прослушка, мониторинг перемещений - сценарии, заложенные разработчиками в технический объект. Под сценариями понимается все то, что следует совершить с объектом. «Сценарии суверенны. Они не растворены в символическом универсуме культуры. Они существуют здесь-и-сейчас и - в отличие от свободно парящих культурных кодов - неотделимы от своего материального носителя» (Вахштайн 2013:13). Это affordance - действия, которые с ним потенциально можно совершить. В компьютерной игре, в логике которой находится взаимодействие с гаджетом, то, что можно совершить, и то, что следует практически совпадает. Однако сценарии могут накладываться друг на друга, порождая метасценарный inscription (28). Взаимодействие, опосредованное гаджетом, рождает множество пользовательских сценариев при фиксированном количестве сценариев использования устройства. Этот теоретический ход требует и теоретической проработки комбинаций складывающихся сценариев. Для этого необходимо ответить на вопросы: что обуславливает формирование каждого конкретного сценария? Насколько сценарий, вписанный в объект, детерминирует метасценарии его использования?

Таким образом, в зависимости от того, что попадает в границы «видимого» при выбранной теоретической оптике, мы увидим разные варианты цифрового родительства: его можно рассматривать и как проявление асимметричного распределения властных ресурсов между детьми и родителями, и как новый способ разметки детского и недетского пространства в цифровом мире, и как дискредитацию идеи приватности мира ребенка, и как наблюдение за преступником, больным или героем виртуальной игры. В конечном счете наиболее сильные концептуализации меняют привычные представления об объекте или формируют новые, которые закрепляются за ним и начинают воспроизводиться в публичных обсуждениях.

\section{СПИСОК ЛИТЕРАТУРЫ}

Вахштайн, Виктор. 2011. Социология повседневности и теория фреймов. СПб.: Изд-во Европейского университета в Санкт-Петербурге.

Вахштайн, Виктор. 2013. «К микросоциологии игрушек: сценарий, афорданс, транспозиция». Логос 2(92):3-37.

Гофман, Ирвинг. 2004. Анализ фреймов. Эссе об организации повседневного опыта. М.: Институт социологии РАН.

Дебор, Ги. 1958. «Теория дрейфа». https://ru.theanarchistlibrary.org/library/gi-debor-teoriya -drejfa.html.

Делез, Жиль. 2004. «Post Scriptum к обществам контроля». С. 226-223 в Переговоры. 19721990. СПб.: Наука.

Джекобс, Джейн. 2011. Смерть и жизнь больших американских городов. М.: Новое издательство. 
Конвенция о правах ребенка. Принята резолюцией 44/25 Генеральной Ассамблеи от 20 ноября 1989 года. https://www.un.org/ru/documents/decl_conv/conventions/childcon.shtml.

Напреенко, Иван. 2015. «Делегирование агентности в концепции Бруно Латура: как собрать гибридный коллектив киборгов и антропоморфов?» Социология власти 27(1):108-121.

Сергеева, Ольга и Елена Лактюхина. 2019. «Социальные аспекты цифровизации детской городской мобильности». Журнал исследований социальной политики 17(4):507-524.

Якимова, Екатерина и Ярослава Евсеева. 2011. «Социология детства в десяти странах: результаты и перспективы». Социальные и гуманитарные науки. Отечественная и зарубежная литература. Серия 11: Социология. Реферативный журнал 2:10-43.

Alanen, Leena. 2005. “Childhood as Generational Condition: Towards a Relational Theory of Childhood." Pp. 286-305 in Childhood: Critical Concepts in Sociology, ed. by Chris Jenks. New York: Routledge.

Ambert, Anne-Marie. 1986. "Sociology of Sociology: The Place of Children in North American Sociology." Pp. 11-34 in Sociological Studies of Child Development, vol. 1, ed. by Patricia A. Adler and Peter Adler. Greenwich, CT: JAI Press.

Barron, Brigid, Caitlin Kennedy Martin, Lori Takeuchi, and Rachel Fithian. 2009. “Parents as Learning Partners in the Development of Technological Fluency." International Journal of Learning and Media 1(2):55-77.

Brito, Rita, Rita Francisco, Patrícia Dias, and Stephane Chaudron. 2017. “Family Dynamics in Digital Homes: The Role Played by Parental Mediation in Young Children's Digital Practices around 14 European Countries." Contemporary Family Therapy 39(4):271-280. doi:10.1007/s10591-017 -9431-0.

Buhler-Niederberger, Doris. 2010. “Introduction. Childhood Sociology: Defining the State of Art and Ensuring Reflection." Current Sociology 58(2):155-164. doi:10.1177/0011392109354239.

Cresswell, Tim. 2006. On the Move: Mobility in the Modern Western World. London: Routledge.

Dias, Patriícia, and Rita Brito. 2020. "How Families with Young Children Are Solving the Dilemma between Privacy and Protection by Building Trust: A Portrait from Portugal." Journal of Children and Media 14(1):56-73. doi:10.1080/17482798.2019.1694552.

Duimel Marion, and Joss de Haan. 2007. New Links in the Family: The Digital World of Teenagers and the Role of Their Parents. The Hague: Sociaal en Cultureel Planbureau.

Forbrukerrådet. 2017. \#WatchOut: Analysis of Smartwatches for Children. https://consumerfed.org /wp-content/uploads/2017/10/watchout-report.pdf.

Foucault, Michel. 2009. "Alternatives to the Prison: Dissemination or Decline of Social Control?" Theory, Culture and Society 26(6):12-24.

Hanson, Karl. 2014. "'Killed by Charity': Towards Interdisciplinary Children's Rights Studies." Childhood 21(4):441-446. doi:10.1177/0907568214547453.

Holloway, Donell, and Lelia Green. 2016. "The Internet of Toys." Communication Research and Practice 2(4):506-519. doi:10.1080/22041451.2016.1266124.

Jeffery, Catherine Page. 2020. “'It's Really Difficult: We've Only Got Each Other to Talk To': Monitoring, Mediation and Good Parenting in Australia in the Digital Age." Journal of Children and Media. doi:10.1080/17482798.2020.1744458.

Jenks, Chris. 1996. Childhood: Critical Concepts in Sociology. New York: Routledge.

Laktyukhina, Elena. 2018. "'Smart Things' in the Child-Parent Interaction: The Statement of the Problem." SHS Web of Conferences 50. doi:10.1051/shsconf/20185001094.

Leaver, Tama. 2017. "Intimate Surveillance: Normalizing Parental Monitoring and Mediation of Infants Online." Social Media + Society 2(3). doi:10.1177/2056305117707192.

Leaver, Tama, and Tim Highfield. 2018. "Visualising the Ends of Identity: Pre-Birth and Post-Death on Instagram." Information, Communication \& Society 21(1):30-45. doi:10.1080/136911 8X.2016.1259343.

Lemish, Dafna. 2015. Children and Media: A Global Perspective. Chichester, UK: Wiley Blackwell.

Livingstone, Sonia. 2002. Young People and New Media: Childhood and the Changing Media Environment. London: Sage Publications. 
Livingstone, Sonia. 2016. "Reframing Media Effects in Terms of Children's Rights in the Digital Age." Journal of Children and Media 10(1):4-12. doi:10.1080/17482798.2015.1123164.

Livingstone, Sonia, and Moira Bovill. 2001. Children and Their Changing Media Environment: A European Comparative Study. Mahwah, NJ: Lawrence Erlbaum.

Livingstone, Sonia, and Monica Bulger. 2014. "A Global Research Agenda for Children's Rights in the Digital Age." Journal of Children and Media 8(4):317-335. doi:10.1080/17482798.2014 .961496 .

Livingstone, Sonia, Leslie Haddon, and Anke Gorzig. 2012. Children, Risk and Safety Online: Research and Policy Challenges in Comparative Perspective. Bristol, UK: The Policy Press.

Mascheroni, Giovanna, Cristina Ponte, and Ana Jorge. 2018. Digital Parenting: The Challenges for Families in the Digital Age. Göteborg, Sweden: The International Clearinghouse on Children, Youth \& Media.

Matthews, Sarah H. 2007. "A Window on the 'New' Sociology of Childhood." Sociology Compass 1(1):322-334.

Moyn, Samuel. 2011. “Reflections on 'The Last Utopia': A Conversation with Samuel Moyn." Journal of Human Rights Practice 3(2):129-138.

Notten, Natascha, and Gerbert Kraaykamp. 2009. “Parents and the Media: A Study of Social Differentiation in Parental Media Socialization." Poetics 37(3):185-200.

Oldman, David. 1994. "Adult-Child Relations as Class Relations." Pp. 43-58 in Childhood Matters: Social Theory, Practice and Politics, ed. by Jens Qvortrup, Marjatta Bardy, Giovanni Sgritta, and Helena Wintersberger. Aldershot, UK: Avebury.

Pinker, Steven. 2002. The Blank Slate: The Modern Denial of Human Nature. New York: Viking.

Qvortrup, Jens. 1991. "Childhood as a Social Phenomenon: An Introduction to a Series of National Reports." Vienna: European Centre for Social Welfare Policy and Research.

Roe, Keith. 2000. "Socio-Economic Status and Children's Television Use." European Journal of Communication Research 25(2):3-18.

Sonck, Nathalie, Peter Nikken, and Jos de Haan. 2014. “Determinants of Internet Mediation." Journal of Children and Media 7(1):96-113. doi:10.1080/17482798.2012.739806.

Star, Susan Leigh, and Geoffrey C. Bowker. 2006. "How to Infrastructure." Pp. 230-245 in The Handbook of New Media: Social Shaping and Social Consequences of ICTs, ed. by Leah A. Lievrouw and Sonia Livingstone. London: Sage.

Valkenburg, Patti M., and Jochen Peter. 2013. "Five Challenges for the Future of Media-Effects Research." International Journal of Communication 7:197-215.

Valkenburg, Patti M., Marina Krcmar, Allerd L. Peeters, and Nies M Marseille. 1999. “Developing a Scale to Assess Three Different Styles of Television Mediation: 'Instructive Mediation,' 'Restrictive Mediation,' and 'Social Coviewing.'" Journal of Broadcasting and Electronic Media 43(1):52-66.

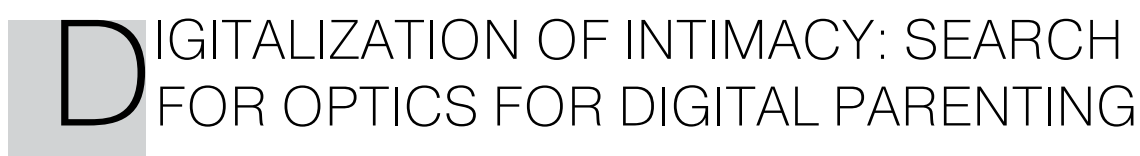

\section{Elena Laktyukhina}

Elena Laktyukhina, Department of Sociology and Social Technologies, Volgograd State University. Address for correspondence: Volgograd State University, Universitetskii pr., 100, Volgograd, 400062, Russia. laktyukhina@volsu.ru. 
This study was funded by the Russian Foundation for Basic Research according to the research project № 18-011-00692 "Parenthood in the Era of 'Smart Things': A Sociological Analysis."

This review article provides a theoretical analysis of the development of digital parenting research. Scholarship in digital parenting may be divided into two corpora of texts: those dealing with the problem of child safety in the digital space and with the problem of ensuring child safety with digital surveillance in everyday life. Analyzing modern concepts of digital parenthood, I mostly focus on the second problem. The essay analyzes the issues of theoretical sources and continuity in the conceptualization of the phenomenon of digital parenting. Proceeding from the thesis that the new sociology of childhood, which is the main engine for the development of parenting research, is methodologically connected with the sociology of everyday life, I address the main concepts of the sociology of everyday life-the structuralist constructivism of Pierre Bourdieu and the frame analysis of Erving Goffman. The purpose of the review essay is to analyze Bourdieu's and Goffman's basic sociology concepts as methodological resources for the conceptualization of digital parenting. Turning to Bourdieusian optics, I use the following concepts: social agents, social relations, resources, social practices, and physical space. Establishing links among them allows to observe most of the problems in the field of digital parenting that have appeared in recent years. In particular, one of the most common interpretations becomes clear: digital monitoring of children by parents is defined as a manifestation of a relationship of domination, an asymmetric distribution of power resources between groups of agents-children and parents. In the theoretical framework proposed by Goffman, technological devices that parents use in relation to their children are considered as things that frame these interactions. Conceptualization in the logic of frame analysis is based on the understanding that observation is the process of constituting the daily practices of children and parents.

Keywords: Digital Parenting; "Smart Things"; Child Mobility; Baby Monitor; Parenthood; Childhood; Privacy

\section{REFERENCES}

Alanen, Leena. 2005. “Childhood as Generational Condition: Towards a Relational Theory of Childhood." Pp. 286-305 in Childhood: Critical Concepts in Sociology, ed. by Chris Jenks. New York: Routledge.

Ambert, Anne-Marie. 1986. “Sociology of Sociology: The Place of Children in North American Sociology." Pp. 11-34 in Sociological Studies of Child Development, vol. 1, ed. by Patricia A. Adler and Peter Adler. Greenwich, CT: JAI Press.

Barron, Brigid, Caitlin Kennedy Martin, Lori Takeuchi, and Rachel Fithian. 2009. “Parents as Learning Partners in the Development of Technological Fluency." International Journal of Learning and Media 1(2):55-77.

Brito, Rita, Rita Francisco, Patrícia Dias, and Stephane Chaudron. 2017. “Family Dynamics in Digital Homes: The Role Played by Parental Mediation in Young Children's Digital Practices around 14 European Countries." Contemporary Family Therapy 39(4):271-280. doi:10.1007/s10591-017 -9431-0.

Buhler-Niederberger, Doris. 2010. “Introduction. Childhood Sociology: Defining the State of Art and Ensuring Reflection." Current Sociology 58(2):155-164. doi:10.1177/0011392109354239.

Cresswell, Tim. 2006. On the Move: Mobility in the Modern Western World. London: Routledge.

Debord, Guy. 1958. “Teoriia dreifa." https://ru.theanarchistlibrary.org/library/gi-debor-teoriya -drejfa.html. 
Deleuze, Gilles. 2004. “Post Scriptum k obshchestvam kontrolia." Pp. 226-223 in Peregovory, 19721990. Saint Petersburg, Russia: Nauka.

Dias, Patriícia, and Rita Brito. 2020. "How Families with Young Children Are Solving the Dilemma between Privacy and Protection by Building Trust: A Portrait from Portugal." Journal of Children and Media 14(1):56-73. doi:10.1080/17482798.2019.1694552.

Duimel Marion, and Joss de Haan. 2007. New Links in the Family: The Digital World of Teenagers and the Role of Their Parents. The Hague: Sociaal en Cultureel Planbureau.

Forbrukerrådet. 2017. \#WatchOut: Analysis of Smartwatches for Children. https://consumerfed.org /wp-content/uploads/2017/10/watchout-report.pdf.

Foucault, Michel. 2009. "Alternatives to the Prison: Dissemination or Decline of Social Control?" Theory, Culture and Society 26(6):12-24.

Goffman, Erving. 2004. Analiz freimov: Esse ob organizatsii povsednevnogo opyta. Moscow: Institut sotsiologii RAN.

Hanson, Karl. 2014. "'Killed by Charity': Towards Interdisciplinary Children's Rights Studies." Childhood 21(4):441-446. doi:10.1177/0907568214547453.

Holloway, Donell, and Lelia Green. 2016. "The Internet of Toys." Communication Research and Practice 2(4):506-519. doi:10.1080/22041451.2016.1266124.

Jacobs, Jane. 2011. Smert' i zhizn' bol'shikh amerikanskikh gorodov. Moscow: Novoe izdatel'stvo.

Jeffery, Catherine Page. 2020. “'It's Really Difficult: We've Only Got Each Other to Talk To': Monitoring, Mediation and Good Parenting in Australia in the Digital Age." Journal of Children and Media. doi:10.1080/17482798.2020.1744458.

Jenks, Chris. 1996. Childhood: Critical Concepts in Sociology. New York: Routledge.

Konventsiia o pravakh rebenka. Priniata rezoliutsiei 44/25 General'noi Assamblei, November 20 1989. https://www.un.org/ru/documents/decl_conv/conventions/childcon.shtml.

Laktyukhina, Elena. 2018. "'Smart Things' in the Child-Parent Interaction: The Statement of the Problem." SHS Web of Conferences 50. doi:10.1051/shsconf/20185001094.

Leaver, Tama. 2017. "Intimate Surveillance: Normalizing Parental Monitoring and Mediation of Infants Online." Social Media + Society 2(3). doi:10.1177/2056305117707192.

Leaver, Tama, and Tim Highfield. 2018. "Visualising the Ends of Identity: Pre-Birth and Post-Death on Instagram." Information, Communication \& Society 21(1):30-45. doi:10.1080/136911 8X.2016.1259343.

Lemish, Dafna. 2015. Children and Media: A Global Perspective. Chichester, UK: Wiley Blackwell.

Livingstone, Sonia. 2002. Young People and New Media: Childhood and the Changing Media Environment. London: Sage Publications.

Livingstone, Sonia. 2016. "Reframing Media Effects in Terms of Children's Rights in the Digital Age." Journal of Children and Media 10(1):4-12. doi:10.1080/17482798.2015.1123164.

Livingstone, Sonia, and Moira Bovill. 2001. Children and Their Changing Media Environment: A European Comparative Study. Mahwah, NJ: Lawrence Erlbaum.

Livingstone, Sonia, and Monica Bulger. 2014. "A Global Research Agenda for Children's Rights in the Digital Age." Journal of Children and Media 8(4):317-335. doi:10.1080/17482798.2014 .961496.

Livingstone, Sonia, Leslie Haddon, and Anke Gorzig. 2012. Children, Risk and Safety Online: Research and Policy Challenges in Comparative Perspective. Bristol, UK: The Policy Press.

Mascheroni, Giovanna, Cristina Ponte, and Ana Jorge. 2018. Digital Parenting: The Challenges for Families in the Digital Age. Göteborg, Sweden: The International Clearinghouse on Children, Youth \& Media.

Matthews, Sarah H. 2007. "A Window on the 'New' Sociology of Childhood." Sociology Compass 1(1):322-334.

Moyn, Samuel. 2011. “Reflections on 'The Last Utopia': A Conversation with Samuel Moyn." Journal of Human Rights Practice 3(2):129-138.

Napreenko, Ivan. 2015. “Delegirovanie agentnosti v kontseptsii Bruno Latura: Kak sobrat' gibridnyi kollektiv kiborgov i antropomorfov?" Sotsiologiia vlasti 27(1):108-121. 
Notten, Natascha, and Gerbert Kraaykamp. 2009. “Parents and the Media: A Study of Social Differentiation in Parental Media Socialization." Poetics 37(3):185-200.

Oldman, David. 1994. "Adult-Child Relations as Class Relations." Pp. 43-58 in Childhood Matters: Social Theory, Practice and Politics, ed. by Jens Qvortrup, Marjatta Bardy, Giovanni Sgritta, and Helena Wintersberger. Aldershot, UK: Avebury.

Pinker, Steven. 2002. The Blank Slate: The Modern Denial of Human Nature. New York: Viking.

Qvortrup, Jens. 1991. “Childhood as a Social Phenomenon: An Introduction to a Series of National Reports." Vienna: European Centre for Social Welfare Policy and Research.

Roe, Keith. 2000. "Socio-Economic Status and Children's Television Use." European Journal of Communication Research 25(2):3-18.

Sergeeva, Olga, and Elena Laktyuhina. 2019. "Sotsial'nye aspekty tsifrovizatsii detskoi gorodskoi mobil'nosti." Zhurnal issledovanii sotsial'noi politiki 17(4):507-524.

Sonck, Nathalie, Peter Nikken, and Jos de Haan. 2014. "Determinants of Internet Mediation." Journal of Children and Media 7(1):96-113. doi:10.1080/17482798.2012.739806.

Star, Susan Leigh, and Geoffrey C. Bowker. 2006. "How to Infrastructure." Pp. 230-245 in The Handbook of New Media: Social Shaping and Social Consequences of ICTs, ed. by Leah A. Lievrouw and Sonia Livingstone. London: Sage.

Vakhshtayn, Victor. 2011. Sotsiologiia povsednevnosti i teoriia freimov. Saint Petersburg, Russia: Izdatel'stvo Evropeiskogo universiteta v Sankt-Peterburge.

Vakhshtayn, Victor. 2013. "K mikrosotsiologii igrushek: Stsenarii, afordans, transpozitsiia." Logos 2(92):3-37.

Valkenburg, Patti M., and Jochen Peter. 2013. “Five Challenges for the Future of Media-Effects Research." International Journal of Communication 7:197-215.

Valkenburg, Patti M., Marina Krcmar, Allerd L. Peeters, and Nies M Marseille. 1999. “Developing a Scale to Assess Three Different Styles of Television Mediation: 'Instructive Mediation,' 'Restrictive Mediation,' and 'Social Coviewing.'" Journal of Broadcasting and Electronic Media 43(1):52-66.

Yakimova Ekaterina, and Yaroslava Evseeva. 2011. "Sotsiologiia detstva v desiati stranakh: Rezul'taty i perspektivy." Sotsial'nye i gumanitarnye nauki. Otechestvennaia i zarubezhnaia literatura. Seriia 11: Sotsiologiia. Referativnyi zhurnal 2:10-43. 